\title{
Direito Social e tecnologias digitais ${ }^{*}$
}

\author{
Derecho social y tecnologías digitales \\ Social Law and Digital Technologies
}

Andrei Koerner"

Eduardo Andrés Perafán Del Campo ${ }^{* * *}$

Data de recepção: 15 de abril de 2020

Data de aprovação: 15 de maio de 2020

\section{Resumo}

Este artigo explora os desafios para a reflexão crítica sobre o Direito impostos pelas mudanças trazidas pela combinação das tecnologias digitais e da racionalidade governamental neoliberal para os modos de governo nas sociedades contemporâneas. Essa combinação tem efeitos sobre o próprio modelo do Direito Social, tal como elaborado pelo constitucionalismo democrático, e é central para o projeto neocosmopolita de Direitos Humanos.

\footnotetext{
Este artigo é o resultado do projeto de pesquisa "Direito, Estado e sociedade", vinculado à linha Direito Constitucional e políticas públicas, do grupo de pesquisa Direito Público e Tecnologias da Informação e Comunicaçâo, G-TICCY, Universidad Católica de Colombia.
}

Citar como: Koerner, A. y Perafán Del Campo, E. A. (2020). Direito Social e tecnologias digitais. Via Inveniendi et Iudicandi, 15(2), 249-276. Dor: https://doi.org/10.15332/625

* $\quad$ PhD e mestrado em Ciência Política pela Universidade de São Paulo, Brasil. Advogado da Universidade Federal de Santa Catarina, Brasil. Presidente do Centro de Estudos de Cultura Contemporânea e professor da Universidade Estadual de Campinas, Brasil. Correio eletrônico: andreiko@uol.com.br. orciD: 0000-0002-4354-9963.

... Doutorando em Ciências Sociais na Universidade de Granada, Espanha. Mestrado em Estudos Políticos e Internacionais e cientista político pela Universidad de Rosario, Colômbia. Editor da revista acadêmica Novum Jus. Professor universitário e pesquisador do grupo de pesquisa em Direito público e tecnologias da informaçáo e comunicação na Faculdade de Direito da Universidad Católica de Colombia. Analista e consultor em assuntos públicos e internacionais. Correio eletrônico: eaperafan@ucatolica.edu.co; eduardoapdc@gmail.com. ORCID: 0000-0002-9981-2679. 
O Direito Social é impactado de duas formas: pelas novas modalidades técnicas de operação do Direito e pela reviravolta das condições sociopolíticas para sua realização. No texto, vemos a reconfiguração do que é o Direito em nossa sociedade e colocam-se em questão seus princípios, conceitos, teorias e técnicas. Assim, a discussão se encontra nas fronteiras entre Direito, política e sociedade, e na confluência de problemas, como as relações entre o Direito e os usos sociais da tecnologia, entre o Direito Constitucional e a democracia, entre os Direitos Humanos e o sistema político internacional.

Este artigo apresenta uma discussão teórica e contextual sobre os efeitos dessa combinação para a ordem constitucional democrática e social, e analisa seu impacto direto e as mudanças possíveis que se deverão produzir no Direito para responder às novas realidades sociais. A análise se concentra nos temas da inteligência artificial e do transumanismo, visto que eles se situam nas fronteiras entre o biológico e o numérico, e colocam a questáo do humano e suas regras nos planos do programa político e dos dispositivos da vida cotidiana.

Palavras-chave: Direitos Humanos, transumanismo, inteligência artificial, neoliberalismo, Direito e Tecnologias da informação e comunicação.

\section{RESUMEN}

El artículo explora los retos para la reflexión crítica del Derecho ante los cambios provocados por la combinación de las tecnologías digitales y la racionalidad gubernamental neoliberal para los modos de gobierno en las sociedades contemporáneas. Esta combinación tiene efectos en el propio modelo de derecho social, tal como lo elaboró el constitucionalismo democrático, y es fundamental para el proyecto neocosmopolita de Derechos Humanos.

El Derecho Social se ve afectado de dos maneras: por las nuevas modalidades técnicas de funcionamiento del Derecho y por el giro en las condiciones sociopolíticas para su realización.

A lo largo del texto, se explora la reconfiguración de lo que es el Derecho en nuestra sociedad y se ponen en tela de juicio sus principios, conceptos, teorías y técnicas. Así, el debate tiene lugar en las fronteras entre el Derecho, la política y la sociedad, y en la confluencia de problemas como las 
relaciones entre el Derecho y los usos sociales de la tecnología, entre el Derecho Constitucional y la democracia; entre los Derechos Humanos y el sistema político internacional.

El artículo presenta una discusión teórica y contextual sobre los efectos de esta combinación en el orden democrático constitucional y social, y analiza su impacto directo y los posibles cambios que deberán tener lugar en el ámbito del Derecho para responder a las nuevas realidades sociales. El análisis se centra en la inteligencia artificial y el transhumanismo, dado que estos se sitúan en las fronteras entre lo biológico y lo numérico y desarrollan la cuestión de lo humano y sus reglas en los planeamientos del programa político y en los dispositivos de la vida cotidiana.

Palabras clave: derechos humanos, transhumanismo, inteligencia artificial, neoliberalismo, derecho y tecnologías de la información y la comunicación.

\section{Abstract}

This article explores the challenges for critical reflection of the law in the face of changes brought about by the combination of digital technologies and neoliberal government rationality for modes of government in contemporary societies. This combination has effects on the social rule of law model itself, as exponded by democratic constitutionalism, and is fundamental to the neocosmopolitan project of Human Rights. Social law is affected in two ways: by the new technical methods for the functioning of the law and by the change in the socio-political conditions for its implementation.

Throughout the text, the reconfiguration of what is Law in our society is explored and its principles, concepts, theories, and techniques questioned. Thus, the debate takes place at the intersection of law, politics, and society, and at the confluence of problems such as the relationship between law and the social uses of technology, between constitutional law and democracy, or between human rights and the international political system.

This article also presents a theoretical and contextual discussion on the effects of this combination on the constitutional and social democratic order, and analyses its direct impact and the possible changes that will have to take place in the field of law to respond to the new social 
realities. The analysis focuses on artificial intelligence and transhumanism, since these lie on the boundaries between the biological and the numerical and develop the question of the human and its rules in the planning of the political agenda and in the devices of everyday life.

Keywords: human rights, transhumanism, artificial intelligence, neoliberalism, law and information and communication technologies. 


\section{INTRODUÇÃO}

Neste artigo, exploramos os desafios para a reflexão crítica sobre o Direito da ordem constitucional democrática e social, impostos pela situaçáo atual caracterizada pela combinação da racionalidade governamental neoliberal e as tecnologias digitais, agravada por eventos políticos recentes. Nossos argumentos são ainda bastante provisórios, pois são o ponto de partida de um projeto de pesquisa ainda em elaboração.

A combinação de neoliberalismo e tecnologias digitais coloca desafios inéditos para a reflexão crítica sobre o Direito. Essa crítica toma o Direito Social como dado, pois ela emergiu historicamente como parte dele, isto é, ele é constitutivo de suas condiçôes de experiência como campo intelectual e atividade prática de reflexão. O Direito Social tem sido, pois, pressuposto e padráo de referência para a crítica ao neoliberalismo; por sua vez, o neoliberalismo produziu, nos últimos 40 anos, impactos no modelo do Direito Social, tal como elaborado pelo constitucionalismo democrático, e que é central para o projeto neocosmopolita de Direitos Humanos. Atualmente, as tecnologias digitais colocam problemas ao Direito em diversos planos, como suas relaçóes com os princípios constitucionais, a elaboração de instrumentos legais e as novas modalidades para sua regulação efetiva.

O processo político recente potencializa essas mudanças com a configuração de uma espécie de neoliberalismo de choque ou de combate. $\mathrm{O}$ uso intensificado de tecnologias digitais faz parte de táticas e açôes que fragilizam, esvaziam ou afrontam abertamente os princípios de Direitos Humanos, os procedimentos políticos e eleitorais, e as formas jurídicas da democracia constitucional.

A situação atual implica discutir a reconfiguração do que é o Direito em nossa sociedade, pois com ela se modificam as condiçóes da produção normativa e as formas sociais de governo dos viventes humanos. Nossa reflexão sobre a crítica ao Direito se realiza na confluência de problemas colocados em diversos campos, como as relaçóes entre Direito e tecnologia, entre Direito e democracia, entre sistema político internacional, Direito Internacional dos Direitos Humanos e Direito Constitucional. Por sua vez, as análises orientadas pelos trabalhos de Foucault sobre a governamentalidade associam o tema 
do neoliberalismo (Dardot e Laval, 2010) às discussóes sobre Direito e tecnologias da informação, e Direito e tecnologias de poder (Golder, 2013).

A análise tem como foco as mudanças no Direito da ordem constitucional democrática e social. Dividimos os problemas impostos pela situação atual em duas ordens inter-relacionadas: (1) a reviravolta das condiçóes políticas, econômicas e sociais para a realização do Direito Social, e (2) as novas maneiras de operação do Direito pelas tecnologias da informação, ilustradas pelos temas do transumanismo e da inteligência artificial. Antes, apresentam-se o marco teórico do trabalho e a contextualização histórica da formação do Direito Social. A discussão teórica servirá de base para colocar os conceitos e as questôes que orientarão nossas pesquisas: quais serão os efeitos produzidos sobre o Direito da ordem constitucional democrática e social pela combinação de governamentalidade neoliberal, mudanças tecnológicas e o programa do transumanismo? Quais os efeitos particulares produzidos pela sua difusão internacional nos próprios anos, nas sociedades latino-americanas, em particular no Brasil, cujo regime constitucional está fortemente abalado pelas crises políticas e econômicas a partir de 2013?

\section{MARCo TEÓRICO}

A partir da releitura de Foucault (1984a, 1984b, 1984c, 2004a e 2004b) e Ewald (1986, 1992 e 1993), adotamos como programa de pesquisa a análise política do pensamento jurídico. Para realizá-lo, propomos as categorias de experiência jurídica, de racionalidade jurídica, de ordem constitucional e de regime constitucional.

O domínio de pesquisa é a experiência jurídica como prática de julgamento que os agentes realizam a respeito da objetividade de suas relaçóes com os outros, consigo mesmos e com o que lhes é comum. Essa objetividade se efetua num espaço conformado por três dimensões: os arranjos institucionais e as estratégias de governo de uma formação social, as formas de pensamento e materiais jurídicos e a história. Além disso, manifesta-se como racionalidade jurídica articulada a uma racionalidade governamental. Racionalidade governamental, ou governamentalidade, refere-se à maneira pela qual se observa, programa e reflete a direção política da sociedade e a condução dos indivíduos. Ela é realizada tanto 
pelas instituiçóes estatais como por outras relaçóes e outros espaços sociais por meio das estratégias de poder de uma formação social (Cortes, 2013).

Por "Direito Social” entende-se a racionalidade pela qual o jurídico se conforma nas sociedades ocidentais contemporâneas, em contraste com o Direito Civil. Esse se caracteriza por sua referência normativa à natureza, o jusracionalismo, e por regras jurídicas editadas pelo soberano, como leis codificadas, com a forma de enunciados condicionais sobre a conduta dos sujeitos, cuja finalidade é a de estabilizar a dominação e assegurar direitos aos indivíduos. As regras jurídicas são conhecidas por um saber dogmático voltado à interpretação dos textos legais e à abstração e à sistematização de conceitos jurídicos. A prática judicial é pensada como operação cognitiva pela qual se subsume o caso individual à lei geral a fim de declarar a regra particular a ele aplicável.

O Direito Social emergiu no século xıx numa configuração epistemológica em que o conhecimento é histórico e relativo, tendo a sociedade como sua referência normativa imanente. As normas jurídicas assumem formas e técnicas diversificadas, pois as regras legais são combinadas com diretivas governamentais e normas disciplinares, que fixam regularidades de comportamentos de populaçóes e parâmetros de normalidade dos indivíduos com fins de gestão. Visa-se a governar a multiplicidade e a extrair utilidade dos corpos, assegurando o equilíbrio dinâmico e a expansão ordenada da sociedade. O jurista é copartícipe na direção da sociedade, uma espécie de gestor das relaçóes entre normas jurídicas, e o conhecimento do Direito se interessa sobretudo pelo aspecto operatório dessas normas. A prática jurídica tem a decisão como modelo: a escolha de meios para a direção governamental da sociedade, no que é chamado de "instrumentalismo jurídico" ou "funcionalização do Direito".

A expressão “ordem constitucional” designa aquilo — que é da ordem do discurso, mas também das tecnologias de poder e das práticas - que liga, enlaça, instituições, espaços e relaçóes sociais para a direção da multiplicidade de agentes, conferindo-lhes uma referência jurídico-normativa objetiva, e conformando-os como sujeitos de direitos (Koerner, 2015). A ordem constitucional indica a maneira pela qual a racionalidade governamental se exerce por meio de uma referência jurídico-normativa em uma determinada sociedade. 
A ordem constitucional assume configuraçóes distintas ao longo do tempo, e se adota uma certa forma que cria a categoria de direitos constitucionais (Montufar e Noguera, 2017), para designar o que pode ser considerado como um regime constitucional.

\section{Perspectiva histórica:}

\section{A ORDEM CONSTITUCIONAL DEMOCRÁTICA E SOCIAL}

O programa do constitucionalismo democrático europeu do pós-Segunda Guerra supera a oposição entre os modelos liberal e comunitário de Constituição:

O constitucionalismo democrático do pós-Segunda Guerra pensa a Constituição como organização material da sociedade, dotada de força normativa, que orienta o ordenamento jurídico e o governo. Seu fundamento é o ser humano como ente racional e moral concreto, considerado em sua individualidade e inserido em grupos naturais e sociais. O princípio da dignidade humana traduz-se na prioridade dos direitos e garantias dos indivíduos em relação aos fins coletivos, enquanto o equilíbrio dos direitos de muitos formula-se em termos de justiça. A jurisdição assume funçóes positivas de assegurar o equilíbrio dos poderes e a promoçáo dos objetivos comuns, ao mesmo tempo que mecanismos institucionais asseguram a articulação dos juízes com os representantes políticos eleitos. (Koerner et al., 2019, p. 201)

A prática jurídica é compreendida como a produção de um saber de caráter construtivo sobre as relaçôes sociais, voltado à concretizaçáo de normas. Se os contornos de sua prática são pouco nítidos, os riscos de arbitrariedade são controlados por padrôes técnicos e éticos da profissão. A objetividade dos juízos é buscada pela apuração técnica da linguagem, pela apreciaçáo exaustiva das provas, pela justificação de escolhas, pelo exame argumentado de alternativas, pelo escrutínio crítico e público da comunidade de intérpretes etc. O jurista aparece como uma espécie de censor, cujo ethos assume o caráter prudencial de sua prática, em que a realização dos fins da Constituição é indissociável da preservação de sua integridade. 
O modelo de Direito Social esteve na base da construção do Direito Internacional dos Direitos Humanos. Desde a Declaração Universal, passando pelas convenções e declarações posteriores e até a Conferência de Viena sobre os Direitos Humanos de 1993, vê-se o investimento na construção de um conjunto de normas, instituições e técnicas jurídicas que tinham como centro o ser humano enquanto vivente concreto. Os temas da dignidade do ser humano e o da criação das condiçóes adequadas ao seu pleno desenvolvimento representavam um foco normativo para o qual se distinguia posiçóes intelectuais e políticas. Por sua vez, ao ser pensado em sua concretude, o ser humano era pensado em função de suas determinações biológicas e condições econômicas, sociais e culturais. Esse quadro conforma os debates ainda atuais sobre o caráter natural ou histórico dos Direitos Humanos, sua universalidade ou seu particularismo, sua dimensão religiosa ou laica, o cosmopolitismo ou a soberania estatal em sua promoção, seus efeitos progressistas ou conservadores com relação à ordem social.

\section{IMPACTOS DA RACIONALIDADE NEOLIBERAL E TECNOlogias digitais Sobre o Direito Social}

No neoliberalismo, o jurídico assegura os direitos de propriedade e de contrato, e mantém as condições do mercado (Bilger, 1963; Commun, 2016). A Constituição e as leis gerais definem o quadro formal dos direitos e das açóes válidas, completadas por medidas regulatórias para preservar o equilíbrio das relaçóes de concorrência e a eficiência da economia. Por sua vez, os direitos sociais têm o papel de assegurar as condiçóes mínimas de existência dos indivíduos. O neoliberalismo de mercado, que emerge nos anos 1970, se opóe à direção estatal da economia a partir da pressuposição da maior eficiência dos mercados, configurando uma racionalidade governamental pela qual a concorrência se coloca como norma objetiva para os agentes e conforma subjetividades segundo o modelo da empresa (Dardot e Laval, 2010, p. 17).

Nesse sentido, a governamentalidade neoliberal

Produziu efeitos amplos sobre a dinâmica das sociedades contemporâneas, desde o aumento da pobreza e das desigualdades até a reorganização do 
aparato produtivo e do Estado. Ele se objetiva em técnicas de governança, que se tornam senso comum, e reconfigura as subjetividades, esvaziando aqueles ideais e desejos dos cidadãos voltados à busca de bens públicos na democracia. (Koerner et al, 2019, p. 202)

Essas mudanças têm impactos nas relaçóes dos indivíduos consigo mesmos, em suas relaçóes privadas com outros, nas formas de vida dos grupos sociais e em suas relaçóes com o governo político da sociedade. O Direito não só dá forma à economia, mas também se torna um meio e um instrumento que faz a economização de novas esferas da vida (Bevir, 2016; Brown, 2015).

\section{NEOLIBERALISMO E ORDEM CONSTITUCIONAL DEMOCRÁTICA E SOCIAL}

O neoliberalismo conforma um novo regime constitucional, que tensiona e redefine as bases da ordem constitucional democrática e social. $\mathrm{O}$ modelo de agente e destinatário das normas passa do ser humano concreto para o indivíduo abstrato maximizador. $\mathrm{O}$ conhecimento jurídico se interessa pelo aspecto operatório das normas, mas essas são definidas de forma abstrata e dedutiva. A regra de justiça e, portanto, também da justiça constitucional (Rodríguez e León, 2015), é modelada segundo a lógica do sujeito-empreendedor de si mesmo, de comportamento maximizador e estratégico, que estabelece relações contratuais com outros e com as agências estatais.

Assim, é possível constatar que a racionalidade governamental neoliberal dos indivíduos orienta a lógica da disseminação das tecnologias de informação e de comunicação nas sociedades:

O modelo da prática do direito torna-se o da análise econômica segundo a qual as normas, interpretaçóes e decisóes são apreciadas do ponto de vista dos seus efeitos para a eficiência. É um método analítico de interpretação da norma, mas de caráter construtivista, porque arranja incentivos e obstáculos para influir sobre a ação futura dos indivíduos. O jurista passa a ser pensado como um gestor-calculador que deve utilizar as margens de apreciação de 
sua atividade para coadjuvar outros técnicos no aumento da eficiência da economia. O próprio Estado, incluindo as instituiçóes judiciais, é encarado do ponto de vista da eficiência, o que leva a reformas de suas organizaçóes, métodos de trabalho e objetivos. Embora o alcance dessas mudanças seja muito desigual nos diversos países, o direito social é redefinido, distanciandose de seu propósito integrador e reformista. O direito constitucional das democracias sociais é formalmente mantido, mas a sua dinâmica democrática e conteúdo social são esvaziados. (Koerner et al., 2019 p. 203)

\section{TeCNOlogias da INFORMAÇÁO E RACIONALIDAdE GOVERNAMENTAL NEOLIBERAL}

Sobre as tecnologias da informação, não é possível superestimar seus impactos sociais nos últimos cinquenta anos. Inicialmente, sob a forma de mainframes, as tecnologias da informação foram adotadas nos campos da pesquisa básica, da indústria de defesa e das grandes corporaçóes. Os computadores pessoais difundiram a informática para todas as facetas da vida cotidiana, ao mesmo tempo que a internet e os telefones pessoais redefiniam por completo as comunicações. Atualmente, as técnicas de inteligência artificial abrem novo campo de utilização intensiva e ampliada da informática na sociedade. Aprecia-se que elas representam uma nova fronteira de mudanças sociais, pois implicam, por exemplo, alteraçóes nas formas de produção e, consequentemente, no emprego, no combate militar e na vigilância sobre a sociedade, assim como nas subjetividades e nas formas de sociabilidade.

No quadro de competição geral entre sujeitos-empreendedores, empresas e Estados, a inovação tecnológica aparece como uma preocupação central do governo da sociedade (Barry, 2001). Os indivíduos, colocados em situação generalizada de concorrência, são incentivados a adotar as tecnologias e a elas se adequarem, pois são apresentadas como potencializadoras de suas capacidades de ação. Os Estados, colocados em situação análoga de concorrência, alteraram a lógica da ação pública, incentivando a inovação, a eficiência e a capacidade de adaptação. Complementarmente, investem no controle dos inaptos e na prevenção e/ou repressão de suas reivindicaçóes. 
Por sua vez, os sistemas de informação e comunicação reestruturam as condiçóes de experiência dos agentes:

[...] produz uma normatividade tecnológica que se impóe como regra objetiva, ao conformar o que é visível, válido e eficaz de maneira que não é construída nem justificada por processos discursivos e refletidos. Ademais, o desenvolvimento dos sistemas de informação segue procedimentos distintos da elaboração das regras de direito na democracia constitucional. Se estas são estabelecidas por um legislador democrático, podem ser violadas e, nesse caso, têm consequências jurídicas; aquelas não são explicitadas, visto que são incorporadas no próprio artefato tecnológico, resultam do desenho e das finalidades visadas por seus engenheiros, estabelecem padróes que possibilitam ou constrangem o comportamento dos agentes, tornando difícil ou impossível a resistência (Hildebrandt, 2016, p. 11) e são constantemente reajustadas. Os sistemas de informação podem ser intencionalmente desenhados para influenciar os agentes, de forma mais ou menos consciente, tendo como escopo regras legais ou outras finalidades, e produzem ainda efeitos não intencionais, implícitos e automáticos (Van den Berg e Leenes, 2013). (Koerner et al., 2019, p. 205)

Produzem-se, portanto, subjetividades descentradas, em que se redefinem as relaçóes entre o corpo, a pessoa e a identidade. Em comum com a governamentalidade neoliberal, a racionalidade instrumental e as interações estratégicas do homo economicus são tomadas como modelo para a estruturação de suas finalidades e alternativas de ação. Mas, como o agente é tomado como consumidor, sentimentos, emoçóes e afetos são incorporados aos sistemas. Essas reflexões tornam-se mais pertinentes com a difusão de sistemas de inteligência artificial baseados no big data, como se verá adiante.

As estratégias de vigilância e de guerra intensificam o uso de tecnologias da informação e de comunicação, especialmente na guerra de quarta geração, tais como a inteligência artificial, o big data ou as redes sociais. Guerras assimétricas, intervençóes militares "cirúrgicas", uso de drones e enfrentamentos no ciberespaço realizam-se em tensão — ou em abolição - com as fronteiras nacionais, bem como com o direito de guerra e o humanitário, os Direitos Humanos e as deliberações das instituições multilaterais. Nesse sentido, Koerner et al. (2019), citando Almeida (2015), propóe que 
[...] a lógica de segurança perpassa os planos internacional e interno dos Estados, e são eliminadas as diferenças entre o cidadáo e o inimigo. Para prevenir açóes que provoquem danos considerados insuportáveis, a vigilância insere-se na esfera da intimidade, tenta decifrar motivaçóes e intençóes cada vez menos conscientes dos agentes. (p. 196)

As geraçôes da guerra é uma classificação acadêmica que torna possível estudar a evolução da guerra. Cada geração responde, ao mesmo tempo, a um diferente contexto político, social, cultural, econômico e temporal. Cada um desses contextos resulta em uma forma particular de entender e empreender a guerra. A partir dessa classificação acadêmica, caracterizamos a forma como a guerra (a principal forma de violência política) é desenvolvida na primeira, na segunda e na terceira geraçấo. Simons (2010) descreve essas três geraçóes da seguinte forma:

A primeira geração de guerra refere-se ao tipo de engajamento típico do período das Guerras Napoleônicas - a era do mosquete "smoothbore", exércitos recrutados, o uso de linha e coluna para maximizar o poder de fogo. A segunda geraçáo de guerra foi uma resposta ao desenvolvimento do cano estriado, da metralhadora e do fogo indireto. Utilizava táticas de fogo linear e movimento e dependia do atrito: a Primeira Guerra Mundial antes da ofensiva alemã da primavera de 1918 constitui um exemplo. Na terceira geraçáo de guerra, em resposta a futuros desenvolvimentos tecnológicos, os exércitos procuram ultrapassar as forças inimigas pela infiltração, em vez de procurar fechar e destruir, e assim transformar as batalhas longe da dependência do desgaste em direçáo à velocidade e à profundidade de manobra. (p. 7, tradução nossa)

Essa descrição enfatiza os aspectos técnicos e o desenvolvimento tecnológico que permitiram o surgimento de novas formas de fazer a guerra em cada uma dessas geraçóes. No entanto, deve ser observado que a criação e o fortalecimento de Estados modernos, o aumento da produção econômica, o crescimento e a expansão das empresas, a implementaçáo de medidas fiscais para o patrocínio da guerra e o surgimento de complexos industriais foram elementos que contribuíram para a evolução da guerra desde a primeira até a terceira geração. 
No plano militar, essas três geraçóes foram caracterizadas pelo protagonismo dos Estados como agentes beligerantes no desenvolvimento de conflitos. Exércitos estatais cada vez mais robustos enfrentaram outros Estados ou coalizóes estatais diretamente no campo de batalha. Geralmente o principal alvo militar era o exército adversário e as açôes de guerra não tinham como foco a população civil. A vitória era determinada pela derrota militar do adversário, que permitia ao Estado vencedor reafirmar seu poder e legitimar suas reivindicaçóes políticas. Exemplos dessas guerras são as Guerras Napoleônicas, a Grande Guerra e a Segunda Guerra Mundial.

Agora, em um contexto de transformaçóes políticas, sociais, culturais e econômicas significativas, emerge a quarta geração de guerras. A era da informação é o terreno fértil para a consolidaçáo dessa nova geração. Com relação a esse tipo de guerra, Simons (2010) sugere o seguinte:

Sua característica distintiva é a assimetria no poder militar entre os combatentes, sendo a parte mais fraca forçada a adotar táticas que evitem enfrentar o esmagador poder de fogo disponível para a outra parte. Essas táticas incluem o sigilo, o uso do terror e a confusão. Exemplos de tais conflitos são claramente anteriores à cunhagem do termo "guerra de quarta geração", especialmente os conflitos coloniais pós-Segunda Guerra Mundial. O termo surgiu no final de um longo debate sobre a natureza mutável de tais conflitos e os meios empregados para financiá-los e vencê-los. Nesses conflitos, uma entidade não estatal, que pode ser designada como um grupo terrorista, tem como objetivo subverter a ordem de um regime estabelecido e substituí-lo por seu próprio governo. (p. 7, traduçáo nossa)

Nesse sentido, as guerras de quarta geração podem ser entendidas como guerras assimétricas. Enfrentamentos bélicos, portanto, são realizados entre atores com características e recursos muito diferentes. Grupos de natureza transnacional entram na cena política internacional e redesenham a forma como a guerra é concebida.

O terrorismo e a guerra de guerrilha são alguns expoentes dessa geração. Os atores irregulares questionam o poder militar do Estado e, tal como assinala Hammes (2005), "está enraizado no preceito fundamental de que a vontade política superior, quando 
devidamente empregada, pode derrotar um maior poder econômico e militar" (tradução nossa). Nesse sentido, o principal objetivo dessa geração é a transmissão de uma mensagem política, o enfraquecimento da imagem e da legitimidade de instituiçóes estatais e a procura de apoio na opinião pública.

É nesse espírito que os combatentes dessa geração não se enfrentam em um campo de batalha particular, mas estabelecem uma rede internacional como plataforma de guerra não convencional. Nem a superioridade militar nem a subjugação do exército adversário são os resultados militares esperados; as principais vitórias nas batalhas que são desenvolvidas consolidam-se como golpes de opiniâo.

Dessa forma, os conflitos bélicos dessa geração assumem a forma de campanhas de comunicação. O sucesso da transmissão da mensagem está ligado à capacidade de comunicação que o grupo irregular possui para posicionar suas abordagens políticas nas redes internacionais de comunicação. Para otimizar esse processo, geralmente envolvem-se ações de natureza terrorista nas quais as principais vítimas não são alvos militares, mas civis. O terror é usado como um elemento fundamental de desestabilização política.

É assim que pode ser observada uma clara ruptura entre as guerras de quarta geração e as formas anteriores de violência política. Como afirma Hammes (2005), "passou de uma era industrial centrada na destruição das forças armadas do inimigo para uma era da informação centrada na mudança de mentalidade dos decisores políticos do inimigo" (p. 254, tradução nossa). Portanto, os preceitos básicos que faziam parte de como foi concebido o desenvolvimento das guerras e do poder militar dos Estados, tais como o número de tropas e o desenvolvimento de armas, não são fatores determinantes para o desenvolvimento das guerras dessa geração. Um exemplo claro dessa situação é a perda da guerra pelos Estados Unidos no Vietnã e os duros golpes que a França sofreu em razão do Daesh.

No entanto, embora as guerras da quarta geração representem novos paradigmas, métodos convencionais de violência política das geraçóes anteriores ainda estão em vigor. $\mathrm{O}$ conceito de guerras híbridas proposto por Hoffman permite-nos evidenciar características das guerras da quarta geração e das guerras convencionais. Para esse autor, é possível encontrar conflitos entre Estados que têm um grande diferencial no poder militar, em 
que o lado mais fraco emprega simultaneamente material e tática de guerra assimétrica e convencional, tudo dependendo da necessidade das operaçóes.

Nesse sentido, poderíamos constatar a continuidade de algumas lógicas das guerras modernas da quarta geração por meio desse conceito em que a Guerra do Líbano de 2006 poderia ser um exemplo. Além disso, embora os Estados não sejam mais os únicos atores com considerável capacidade bélica, eles continuam a ser uma referência fundamental no desenvolvimento da guerra. Na luta contra grupos terroristas e outros atores irregulares, os Estados continuam a ser protagonistas tanto individual como supranacionalmente. Organizaçóes supranacionais como a Organização do Tratado do Atlântico Norte têm desenvolvido estratégias claras para enfrentar a emergência de enfrentamentos assimétricos (Instituto de Estudios Geoestratégicos y Asuntos Políticos, 2011).

\section{O FIM Do Direito? As TECNOLOGIAS dA INFORMAÇÃo E}

\section{COMUNICAÇÃo E AS MUdANÇAS NA PRÁTICA do DireITo}

As tecnologias da informação e comunicação produziram impactos sociais amplos, com novos arranjos de instituiçóes, artefatos e práticas, e tornaram-se objeto de debate público. Seus efeitos sobre o direito são diversificados, tais como os tipos de casos e questóes para julgamento, os domínios para a regulamentação, os conceitos e as técnicas. Além disso, também se inserem nos aspectos organizacionais dos tribunais e nas práticas jurídicas, bem como na formulação de modelos teóricos sobre o Direito baseados na cibernética (Bourcier et al., 2000; Doat et al., 2006). Destacam-se os problemas para os direitos civis, postos pelo uso de técnicas de informação e de modelos estatísticos para a vigilância no ciberespaço, a política criminal e ações preventivas contra atentados terroristas e outros eventos indesejáveis, como acidentes ambientais ou sanitários (Dieter, 2013; Almeida, 2015).

A esse respeito, o surgimento do ciberespaço e os problemas associados às características específicas desse cenário levaram a repensar algumas das ideias e das funçóes substantivas dos Estados. Por exemplo, as ideias tradicionais de soberania tornam-se difusas e resultam em novas formas de exercer o poder soberano. Em particular, o controle sobre 
a experiência do cybernaut e o conteúdo acessível a partir de plataformas web interconectadas transformam-se em novos desafios aos quais os Estados estão respondendo, até determinado ponto, com base no Direito.

As ameaças resultantes do uso das tecnologias de informação e comunicação estão em constante mudança e se adaptam facilmente aos esforços de regulamentação e aplicação do Direito. A condiçáo burocrática do Direito que Weber indicou em seu tempo, e que em grande medida ainda hoje nos acompanha, significa que ele muitas vezes se mostra incapaz de regular e exercer um papel eficaz diante de tais ameaças. Parece que, como afirma Bauman (2015), o uso do Direito como ferramenta para enfrentar as ameaças que surgem de um mundo interconectado e globalizado não é suficiente e poderia colocar o Estado em uma competição na qual seria difícil vencer.

Uma importante bibliografia tem usado os conceitos de guerra e estado de exceção para analisar a combinação de racionalidade neoliberal, capitalismo financeirizado, combate ao terrorismo e tecnologias da informação (Agamben, 2015; Alliez e Lazzarato, 2016). A presente pesquisa enfoca essa situação tensa como uma nova normalidade, que pode ser vista em diversos aspectos das sociedades atuais (Barry, 2001; Miller e Rose, 2008; Supiot, 2015).

Um ponto focal desse tema é o princípio, achado ou modelo operacional resultante da convergência das ciências nano, bio, de informação e cognitiva (NBIC): o de que no nível nano não há diferença entre o que é vivo e o que não o é. $\mathrm{O}$ vivente se tornou um campo de operaçóes tão amplo, aberto e maleável quanto qualquer outro.

O objetivo da pesquisa é analisar a situação emergente como uma nova normalidade, explorando as relações entre dois temas: a inteligência artificial e o transumanismo. Eles se situam nas fronteiras entre o biológico e o numérico, e colocam a questão do humano e de suas regras nos planos do programa político e dos dispositivos da vida cotidiana. Por meio da inteligência artificial, máquinas simulam as operações racionais de selecionar e arranjar os meios para alcançar de forma eficiente finalidades estabelecidas. Elas oferecem as bases para veredictos sobre personalidades, comportamentos e relaçóes sociais. Por sua vez, humanos incorporam aparatos e técnicas para melhor se adaptarem ao ambiente, ampliarem suas perspectivas e aumentarem seu desempenho (Koerner et al., 2019). 


\section{INTELIGÊNCIA ARTIFICIAL E SEUS CRÍTICOS}

A inteligência artificial é um campo tecnológico unificado em torno do tema do agente inteligente. Ela busca não só entender como pensamos, mas também construir entidades inteligentes capazes de ação. Para isso, sistematiza e automatiza tarefas intelectuais em toda área de atividade. Desenha um programa de agente que implementa uma função, por meio do mapeamento das suas percepçóes do ambiente e de seus procedimentos para realizar as açóes desejadas e adequadas aos fins visados. Para tanto, os agentes de inteligência artificial são capazes de aprendizado em razão das mudanças de informações do ambiente e da avaliação da própria performance (Russel e Norvig, 2003).

Se a área foi inicialmente vista como utópica e demasiadamente otimista, na última década, disseminaram-se na sociedade máquinas inteligentes que desempenham funções específicas. Avalia-se que esse processo é o início de uma transformação produtiva de larga escala, colocada como uma nova revolução produzida pela informática. Os efeitos sociais não deixaram de ser criticados pelos que colocam questôes alarmistas sobre a impossibilidade de os humanos controlarem máquinas superinteligentes, ou pelos que levantam os problemas éticos da relação de humanos com máquinas que pensam, ou têm consciência (Barrat, 2015; Besnier, 2012).

Além disso, os crescentes desenvolvimentos em inteligência artificial aplicados a várias esferas da vida humana se aprofundaram, especialmente naqueles cenários que permitiram a otimização dos processos industriais e maiores benefícios econômicos. A inteligência artificial é um dos pilares da chamada "Quarta Revolução Industrial", que se propõe não só repensar os processos industriais por meio da automação da internet das coisas, entre outros, mas também reconfigurar, de certo modo, a própria ideia do que é ser humano.

Nesse sentido, as transformaçóes que a inteligência artificial introduzirá na sociedade em geral levam-nos a pensar em um cenário em que o Estado, com base no Direito e de acordo com as dinâmicas que possibilitam as transformaçóes na esfera estadual (Carvajal, 2017), terá que ponderar possíveis conflitos para salvaguardar alguns dos fundamentos democráticos de natureza social. Entretanto, partindo de uma racionalidade governamental de natureza neoliberal, em que há uma série de elementos axiológicos condicionados pela máxima eficiência econômica, não é totalmente claro o resultado dos cálculos de custo e benefício 
que os Estados terão de fazer; cálculos que terão em sua essência um entendimento particular da justiça (Giraldo e Galán, 2015). Talvez uma das maiores preocupaçóes com relação à incursão da inteligência artificial nos processos produtivos seja a possível substituição do trabalho humano. A incerteza diante da possível perda de empregos, especialmente no que concerne às populações em condiçóes que as torna mais vulneráveis (Salazar, 2017), é apenas um dos desafios que o Estado terá de assumir com crescente urgência.

De um ponto de vista imediato, são previsíveis os impactos sociais das tecnologias, especialmente sobre os trabalhos rotineiros, nos quais a mão de obra não qualificada ou semiqualificada poderá ser substituída em pouco tempo. Mas os impactos abarcam todas as áreas da economia, da pesquisa e do ensino às estratégias militares, ao lazer e às formas de sociabilidade.

$\mathrm{Na}$ confluência da racionalidade neoliberal e das técnicas de inteligência artificial estão em jogo as formas de objetivação e subjetivação de agentes e suas relaçóes, assim como as possíveis formas de resistência, de regulação e de construção de alternativas à racionalidade governamental emergente.

Outros problemas revelam o acoplamento de modelos matemáticos e a racionalidade governamental neoliberal. Em áreas tão variadas, como tribunais, bancos, empresas, escolas e hospitais, adotam-se sistemas de auxílio à tomada de decisão para gerar a solução mais eficiente a partir do tratamento de grande número de casos. Mas os modelos desses sistemas são muitas vezes opacos e enviesados. Com bases de dados limitadas, eles realizam inferências duvidosas e correlaçóes espúrias, e não se tem a possibilidade de corrigir ou verificar as informaçóes adotadas:

O critério de avaliação do desempenho dos indivíduos é o sucesso, sob o ponto de vista da organização ou do operador do sistema, diante do qual os atributos individuais se tornam fatores de risco. Algoritmos que selecionam aspectos determinados da realidade em função dos objetivos visados tornamse produtores de verdade, objetivando os indivíduos e justificando as decisóes que afetam seus interesses, direitos e oportunidades (O’Neil, 2016). Adotamse esquemas de vigilância que se baseiam no princípio da precaução para aumentar a segurança. Presume-se que os indivíduos agem segundo uma 
racionalidade estratégica, calculadora e maximadora, e que observam as leis e se conformam às normas táo somente em virtude da estrutura de incentivos e puniçóes posta em ação por aqueles esquemas. Busca-se criar instrumentos mais refinados de predição comportamental, para que se adotem técnicas cujas premissas são a desconfiança e a suspeita. Para isso, utilizam intensivamente as TIC, que disponibilizam constantemente uma panóplia de novas técnicas e artefatos tecnológicos, tais como algoritmos baseados em aprendizado de máquina (machine learning), mineração de dados (data mining), e o uso massivo de dados (big data). (Koerner et al., 2019, p. 204)

Entretanto, a partir da racionalidade governamental neoliberal que maximiza a eficiência, o big data consolida-se como um desafio e uma grande oportunidade para otimizar os processos burocráticos do Estado, a tomada de decisóes em políticas públicas e, inclusive, o acesso a informaçóes-chave que permitam orientar a opinião pública e definir cenárioschave de deliberação política como as eleições. Entretanto, esses cenários, nos quais é possível fazer uso do big data para tornarem mais eficientes certos processos relacionados com trabalho do Estado e com a vida política em geral, convergem em discussóes fundamentais relativas à obtenção e ao tratamento de tais dados. Essas discussóes orbitam em torno de elementos, como a privacidade, diante dos quais a capacidade reguladora da lei está mais uma vez comprometida.

\section{O TRANSUMANISMO}

O transumanismo coloca-se como um programa político que elogia as mudanças tecnológicas articulando-as à governamentalidade neoliberal. Ele se forma a partir dos anos 1980 como um movimento que propóe a evolução dirigida pela vontade humana, assistida pela ciência. Dessa forma, o transumanismo afirma a possibilidade e o desejo de usar a tecnologia para melhorar a condição humana (Hansell e Grassie, 2011; More e Vita-More, 2013) e suas performances físicas, intelectuais e emocionais.

O transumanismo embaralha as fronteiras entre indivíduo e máquina, cuja combinação permitiria ampliar o humano pelas tecnociências. A melhoria se daria de diferentes formas, tais como pela transição dos seres humanos de carne para os de eletrônica; pela 
mudança de sua morfologia com a incorporação de dispositivos tecnológicos ao corpo; pela transferência da mente para uma máquina; pela criação por máquinas dotadas de atributos humanos, como a consciência e a sensibilidade; pela formação de redes mentais por meio da conexão (internet das coisas); pela habitação de outros planetas por humanos.

O transumanismo desvaloriza o ser humano e seu corpo biológico - marcado pela imperfeição e pela degradação - para criar um ente com capacidades decuplicadas. O aperfeiçoamento seria necessidade vital dado o avanço técnico das sociedades, mas haveria a possibilidade de uma evolução deliberada para liberar o indivíduo da biologia. $\mathrm{O}$ aumento das capacidades físicas e intelectuais dos indivíduos ampliaria sua adaptabilidade e eficiência.

Ao se centrar na adaptação e no aperfeiçoamento do indivíduo, o transumanismo está inserido no discurso neoliberal focado na performance e na competição ilimitadas do homo economicus. Os transumanistas afirmam ser continuadores do ideal iluminista, mas levam às últimas consequências a despolitização e a desencarnação do ideal humanista da perfectibilidade. Isso porque se coloca numa lógica adaptativa centrada na transformação do indivíduo e da vida antes da transformação da sociedade (Le Dévédec, 2015; Ferry, 2016).

Embora o transumanismo tenha ainda alcance limitado, seu potencial de difusão é bastante grande. $\mathrm{O}$ movimento tem vínculos com a elite intelectual, o governo e as grandes corporaçóes norte-americanas. Suas atividades são financiadas pelos gigantes das tecnologias da informação. Seus integrantes se organizam em associações internacionais, estabelecem parcerias com universidades, grupos de pesquisa e think tanks, e têm até partidos políticos nos Estados Unidos.

Seus principais mentores (Ray Kurzweil, Eric Drexler, Max More, Nick Bostrom) lideram uma associação internacional e são muito ativos na internet. Participaram do projeto de convergência das tecnologias NBIC, de 2002, financiado pela National Science Foundation. Além disso, colaboram com as Forças Armadas norte-americanas e organizaram a University of Singularity, no Vale do Silício, financiada pelos gigantes da indústria da informação — Google, Apple, Microsoft (Ferry, 2016). 
Assim, o transumanismo é mais do que uma doutrina ou utopia imaginativa, pois é um movimento político-cultural que se situa na fronteira entre inovação tecnológica e racionalidade governamental neoliberal. Seu potencial de influência é ainda maior se considerarmos que se trata de um programa que combina técnicas de objetivação das relaçóes sociais com a subjetivação dos agentes, e que se articula com interesses das grandes corporaçóes e do Estado norte-americano.

\section{Críticas ao Transumanismo}

O transumanismo recebeu críticas diversas, de ordem ética, política e econômica. Um tema ético fundamental é o princípio de que o humano se torna equivalente a qualquer matéria, ou seja, descartável. O transumanismo criaria super-humanos, que não têm a experiência da condição humana e não compartilham de nossa sensibilidade, medos e projetos. Eles poderiam considerar insatisfatório o controle exercido pelos humanos sobre eles e usar sua superioridade para controlar os humanos (Palomares e Calonje, 2015).

Efeitos mais concretos e previsíveis são as implicações dos interesses financeiros, políticos e militares norte-americanos para o investimento, a produção e a difusão do programa transumanista e das tecnologias digitais. Especula-se sobre os impactos negativos ou não esperados dessas tecnologias — podem funcionar mal, ser incontroláveis, realizar açóes imprevisíveis, reagir com outras tecnologias.

Há trabalhos catastrofistas segundo os quais máquinas superinteligentes usariam suas capacidades para se subtraírem do controle humano, com a ruptura ou a catástrofe de nossa sociedade. Mas as especulaçóes colocam-se muitas vezes na interação entre indivíduo-máquina ou, em outros termos, entre humanos e super-humanos. Seria importante considerar o problema de uma ótica política, ou seja, das relaçóes de governo entre humanos, com capacidade extremamente desigual de organizarem seus conhecimentos, interesses e valores.

Destaca-se que há desigualdade e oscilação das posições. Os humanos (corporaçóes e universidades, por exemplo) capazes de criar super-humanos são considerados como 
superiores a esses últimos. Os viventes humanos comuns são os destinatários, beneficiários e alvos, ou cobaias, da tecnologia.

Porém, quando consideramos os perigos postos pelos super-humanos criados, seus criadores retornam à posição dos viventes humanos (ou seja, dos indivíduos comuns). Os criadores de super-humanos aparecem agora como alvos, e eles são reduzidos à condição humana vulnerável diante dos riscos das tecnologias. Essa oscilação da posição dos criadores de super-humanos indica que eles não são adequadamente analisados como grandes corporaçóes dotadas de conhecimentos perigosos que se afirmam sobre o humano com o objetivo de maximizar as utilidades que dele possam extrair (Rodríguez, 2014).

Por sua vez, os viventes humanos comuns são sempre mantidos na posição passiva de alvos, ou receptáculos, dos experimentos e das ações da técnica. Assim, a análise política precisa sair dessa abordagem e pensar o campo estratégico do problema. Ele consiste nas relaçóes de governo, de produção de verdade e de subjetividades. O ponto de partida da análise é a variedade de relaçóes entre os sujeitos, seus interesses e conflitos, tanto sobre as formas de produção quanto sobre os efeitos das tecnologias digitais.

No entanto, o transumanismo é apenas uma das expressóes das expectativas e dos temores relativos às tecnologias digitais. A atenção ao transumanismo e à inteligência artficial abre um campo de trabalho bastante diversificado de debates sobre tecnologia e poder na atualidade. Por exemplo, ante os transumanistas, há os conservacionistas, e os cristãos se posicionam no debate. Há os temas da engenharia genética, das mudanças ambientais, da vigilância, da indústria de defesa e das formas de guerra.

Os debates sobre o meio ambiente aparecem como complementares à alteração do humano, pois em ambos o centro da questão é o estabelecimento de um numérico intercambiável. Manipulam-se informações e moléculas para gerir as relaçóes entre o vivente humano e seu ambiente. Esse numérico é equivalente ao dinheiro e se pretende governar os indivíduos na interseção entre sua materialidade corpórea, seus desejos e sua consciência. Desse modo, as discussóes sobre transumanismo e inteligência artificial implicarão uma programação de longo prazo para elaborar projetos específicos de pesquisa. 


\section{Conclusão}

O Direito Social é uma racionalidade jurídica que procurou acoplar as normas do Direito à normatividade imanente social, por meio de uma forma de conhecimento científicosocial que adequaria as relaçóes entre o sistema político, o sistema jurídico e as dinâmicas da economia e da sociedade.

A ordem constitucional democrática e os Direitos Humanos colocam o projeto reformista para promover a dignidade humana, considerando os seres humanos como ente histórico concreto. Eles são tomados como inseridos em grupos naturais e sociais, aguilhoados por necessidades e capazes de agência, isto é, de interpretar, refletir e agir sobre o meio social. As políticas reformistas democráticas assumiram duplo aspecto: os cidadáos como entes individuais e coletivos, que teriam a condição de autores e destinatários das normas jurídicas e políticas públicas, cujo intuito seria de governá-los e, ao mesmo tempo, de ampliar sua capacidade de ação e reflexão.

O neoliberalismo esvazia a ordem constitucional democrática porque o programa de participação política para a construção de projetos coletivos de reformas sociais é substituído pelo governo dos agentes do ponto de vista unilateral de sua condição de entes dotados de desejos e voltados à realização de seus objetivos próprios.

O conhecimento jurídico da ordem constitucional democrática assume um caráter construtivista, interpretativo da sociedade e concretizante das normas. O saber jurídico neoliberal é construtivista, mas enfoca os dados de cada situação do ponto de vista de seus efeitos econômicos.

As tecnologias digitais, ao se disseminarem segundo a racionalidade governamental neoliberal, abrem novos campos de inovação técnica e padrōes para a busca da eficiência, para a construção de saberes e para o investimento em formas de subjetividade adequadas à ordem social competitiva.

O transumanismo investe na conformação de novas subjetividades. Em busca da plena autorrealização, os indivíduos produzem formas de vida nas quais os aparatos técnicos 
são plenamente integrados em suas atividades cotidianas, em seu corpo, em seus projetos, em seus desejos.

Enfim, a combinação entre a racionalidade governamental neoliberal, as tecnologias digitais e o transumanismo aprofunda os desafios para o pensamento jurídico crítico. Ela desloca o campo da racionalidade do Direito Social, dado que o Direito passa de um saber científico-social problematizante para um saber formal e funcional, que se constrói por modelos matemáticos, nos quais as normas são conhecidas do ponto de vista operatório para realizar funções específicas.

Os agentes, que eram pensados como seres sociais concretos e finitos, agora passam a ser entes modelados, com objetivos e funçóes predefinidos e destinatários de incentivos e restriçôes. Em suma, a capacidade de aprendizado das máquinas é relevante do ponto de vista da resolução de problemas, mas é unilateral e estreita ao eliminar os espaços para a deliberação coletiva, as significaçóes associadas ao contexto, o imprevisto, a emoção. Pode-se vislumbrar uma definição do Direito como as diretivas produzidas por máquinas de julgar que geram vereditos voltados a estabilizar situaçóes que envolvem agentes humanos que se imaginam máquinas e entes artificiais dotados de atributos humanos.

\section{REFERÊNCIAS}

Agamben, G. (2015). Estado de Exceção. São Paulo: Boitempo.

Alliez, E. e Lazzarato, M. (2016). Guerres et capital. Paris: Éditions Amsterdam.

Almeida, A. O. de. (2015). Terrorismo e direitos humanos: três ensaios críticos [Dissertação de mestrado em Ciência Política, Unicamp]. Repositório da Produção Científica e Intelectual da Unicamp.

Barrat, J. (2015). Our Final Invention - Artificial Intelligence and the End of the Human Era. New York: St Martin Griffin.

Barry, A. (2001). Political Machines - Governing a Technological Society. Londres e Nova York: The Athlone Press.

Bauman, Z. (2015). Modernidad líquida. México: Fondo de cultura económica. 
Besnier, J. M. (2012). Demain les posthumains - Le futur a-t-il encore besoin de nous? Paris: Fayard.

Bevir, M. (2016). Governmentality after Neoliberalism. Nova York: Routledge.

Bilger, F. (1963). La pensee économique libérale en Allemagne contemporaine. Paris: LGDJ.

Bourcier, D., Hassett, P. e Roquily, C. (2000) Droit et intelligence artificielle - Une révolution de la connaissance juridique. Paris: Romillat.

Brown, W. (2015). Undoing the Demos - Neoliberalism's Stealth Revolution. Nova York: Zone Books.

Carvajal, J. E. M. (2017). Transformaciones del derecho y del estado un espacio de reflexión de Novum Jus. Novum Jus, 11(2), 7-12.

Commun, P. (2016). Les Ordolibéraux - Histoire d'un libéralisme à l'Allemande. Paris: Les Belles Lettres.

Cortes, S. (2013). La globalización económica y los derechos humanos. Revista Via Inveniendi et Iudicandi, 8(2), 138-149.

Dardot, P. e Laval, C. (eds.). (2010). La nouvelle raison du monde. Paris: La Decouverte.

Dean, M. Foucault, Government and the Enfolding of Authority. (1996). Em A. Barry, T. Osborne e N. Rose (eds.), Foucault and Political Reason - Liberalism, Neo-liberalism and the Rationalities of Government (pp. 189-208). Londres e Nova York: UCL Press.

Dieter, M. S. (2013). Politica criminal atuarial — a criminologia do fim da história. Rio de Janeiro: Revan.

Doat, M., Le Goff, J. e Pedrot, P. (2006). Droit et compléxité: pour une nouvelle intelligence du droit vivant. Rennes: Presses Universitaires de Rennes.

Ewald, F. (1986). L'État providence. Paris: Grasset.

Ewald, F. Michel Foucault et la norme. (1992). Em L. Giard (ed.), Michel Foucault, Lire l'Oeuvre. Grenoble: Jerome Millon.

Ewald, F. (ed.). (1993). Foucault, a norma e o direito. Lisboa: Vega.

Ferry, L. (2016). La révolution transhumaniste. Paris: Plon. 
Foucault, M. (1984a). História da sexualidade - o uso dos prazeres (vol. 2). Rio de Janeiro: Graal.

Foucault, M. (1984b). Le pouvoir: comment s'exerce-t-il? Em H. Dreyfuss e P. Rabinow (eds.), Michel Foucault - Un parcours philosophique (pp. 308-321). Paris: Gallimard.

Foucault, M. (1984c). Pourquoi étudier le pouvoir: la question du sujet. Em H. Dreyfuss e P. Rabinow (eds.), Michel Foucault - Un parcours philosophique (pp. 297-307). Paris: Gallimard.

Foucault, M. (2004a). Securité, territoire, population - Cours au Collège de France, 19771978. Paris: Gallimard/Seuil.

Foucault, M. (2004b). Naissance de la biopolitique - Cours au Collège de France, 1978-1979. Paris: Gallimard/Seuil.

Giraldo, O. A. A. e Galán A. R. (2015). Derecho injusto: fórmula de universalización y derechos humanos. Novum Jus, 9(2), 111-136.

Golder, B. (Ed.). (2013). Re-reading Foucault: On Law, Power and Rights. Nova York: Routledge.

Hammes, T. (2005). War evolves into the fourth generation. Contemporary Security Policy, 26(2), 189-221.

Hansell, G. e Grassie, W. (eds.). (2011). H+/- Transhumanism and its critics. Philadelphia: Metanexus Instituteed.

Instituto de Estudios Geoestratégicos y Asuntos Políticos. (2011). Guerras de cuarta generación. Bogotá: Universidad Militar Nueva Granada.

Koerner, A. (2015). Direito e tecnologias de poder. Estudos de Sociologia, 20(38), 57-73.

Koerner, A., Vasques, P. H. e Okura, A. (2019). Direito social, neoliberalismo e tecnologias de informação e comunicação. Lua Nova: Revista de Cultura e Politica, (108), 195-214.

Le Dévédec, N. (2015). La société de l'amélioration — la perfectibilité humaine des Lumières au transhumanisme. Montreal: Liber.

Montufar, A. M. e Noguera D. (2017). Garantía de los derechos constitucionales de los pueblos indígenas en el multinacionalismo y el neoconstitucionalismo. Novum Jus, 11(2), $19-51$. 
More, M. e Vita-More, N. (2013). The Transhumanist Reader. Hoboken, Nova Jersey: Wiley-Blackwell.

Ortegón D. R. e Molina J. E. L. (2015). La lógica de la función judicial: análisis en marco de la justicia constitucional. Novum Jus, 9(2), 95-110. https://doi.org/10.14718/ NovumJus.2015.9.2.4

Palomares, J. e Calonje, N. (2015). Tratados de libre comercio Colombia-Asia: cuestión preliminar y perfiles de negociación. Revista Iusta, 43(1), 17-41.

Rodríguez, A. (2014). Indicadores de constitucionalidad de las políticas públicas: enfoque de gestión de derechos. Revista Via Inveniendi et Iudicandi, 9(2), 135-175.

Russel, S. e Norvig, P. (2003). Artificial Intelligence - A modern approach. Hoboken, Nova Jersey: Pearson Education.

Salazar, M. A. (2017). Incidencia de las normas internacionales para la protección de los trabajadores migrantes irregulares en Colombia. Novum Jus, 10(2), 89-101.

Simons, G. (2010). Fourth generation warfare and the clash of civilizations. Journal of Islamic Studies, 21(1), 391-412.

Supiot, A. (2015). La Gouvernance par les Nombres - Cours au Collège de France (20122014). Paris: Fayard, Institut d'Études Avancées de Nantes.

Weber, M. (1964). Economía y sociedad (J. Medina Echavarría, J. Roura Farella, E. Ímaz, E. García Maynez y J. Ferrater Mora, trads.). México: Fondo de Cultura Económica. 